\title{
FUNGSI DAN PROSES PEMBUATAN TOPENG DI KABUPATEN MALANG JAWA TIMUR
}

Function and Making Process of Mask in Malang, East Java

\author{
Robbi Hidajat \\ Staf Pengajar Jurusan Seni dan Desain, Program Studi Pendidikan Seni Tari dan Musik \\ Fakultas Sastra Universitas Negeri Malang, Indonesia \\ Telp.081234230924, E-mail: gantargumelar@gmail.com
}

Tanggal Masuk Naskah: 12 Maret 2014

Tanggal Revisi Naskah: 10 Juni 2014

\begin{abstract}
ABSTRAK
Topeng Malang adalah salah satu jenis topeng Jawa yang berkembang di Malang Jawa Timur. Memperhatikan bentuk raut topeng yang digambarkan tergolong dalam genre tokoh-tokoh lakon Panji. Topeng berfungsi sebagai properti seni pertunjukan Wayang Topeng. Penelitian ini merupakan kajian fungsi, baik dari sisi kegunaan material dan teknik pembuatan topeng. Permasalahan penelitian ini ada 2, yaitu (1) apakah fungsi Topeng Malang, (2) bagaimana teknik dan proses pembuatan Topeng Malang. Informan penelitian adalah perajin. Teknik pengumpulan data menggunakan observasi dan wawancara mendalam. Teknik analisis adalah interpertasi simbolis. Hasil penelitian ini adalah deskripsi tentang fungsi wayang topeng sebagai alat untuk menutup wajah penari agar sebagai bentuk penyamaran bagi penari agar dapat melakukan komunikasi spiritual dengan roh leluhur untuk mengharapkan berkah kesuburan. Teknik dan proses pembuatan Topeng Malang yaitu teknik ukir menggunakan pisau pangot. Proses pembuatannya terdiri dari 4 tahap, mbakali, wiwit, meraeni, dan maesi. Tiga tahap proses ini berelasi dengan proses penggarapan lahan sawah.
\end{abstract}

Kata kunci: topeng, teknik, wayang, kerajinan

\begin{abstract}
Mask of Malang is a type of Javanese masks which develop in Malang, East Java. From the face form, the masks portray the figures from Panji tales. The main function of the masks is as a property in Mask Puppet art performance. This research is a study of functions, both in terms of material usability and mask making techniques. The problems discussed in this study are, (1) what the mask of Malang's function is, (2) how the mask making technique and process are. Research informants are craftsmen. Data collection methods are by observation and interviews. Analysis methods are by symbolic interpretation. The results of this study are description of mask puppet as an equipment to cover the dancer's face, as a camouflage in order to communicate spiritually with ancestors' spirits to ask for blessings of prosperity. The mask making techniques and processes are using carving technique by pangot knives. The making process consist of four steps: mbakali, wiwit, meraeni, and maesi. The three steps of this process are related to paddy cultivation process.
\end{abstract}

Keywords: mask, technique, puppet, craft 


\section{PENDAHULUAN}

Nilai-nilai budaya etnik yang telah tumbuh pada masa lalu masih digunakan sebagai orientasi pandangan masyarakat masa kini, pola pikir dan perilaku hidup masyarakat tradisional tetap bermakna sebagai spirit, ruh, dan jiwa kehidupannya (Gustami, 2006). Para Wali, terutama Sunan Kalijaga adalah pengembang tradisi pembuatan topeng Jawa. Sunan Kalijaga-lah yang selalu dikatakan sebagai pencipta topeng-topeng untuk pertunjukan Wayang Topeng pertama pada permulaan abad ke-16 (Soedarsono, 1997). Dalam mencipta topeng-topeng itu diceritakan Sunan Kalijaga berkiblat pada mula bonekaboneka kulit dari pertunjukan Wayang Gédhog yang membawakan cerita Panji. Topeng dan cerita panji di Jawa adalah salah satu orientasi pandangan masyarakat yang hingga kini masih dapat dihayati masyarakat Jawa (Hidajat, 2008).

Pertunjukan Wayang Topeng yang pertama Sunan Kalijaga membuat sembilan topeng, yaitu untuk tokoh-tokoh Panji Kesatriyan, Candrasih, Gunungsari, Andogo, Raton (Raja), Klana, Danawa (raksasa), Renco (sekarang Témbém) atau Dhoyok, dan Turas (sekarang Pénthul atau Bancak) (Soedarsono, 1997). Jumlah nilai sembilan berasal dari kedudukan para Dewa Hindu. Kemudian di Jawa mengalami penafsiran ulang. Sehingga nilai sembilan tidak menonjol. Pemahaman itu banyak ditemuakan menjadi nilai empat (papat) yang disebut dengan keblat dan satu titik di tengah yang disebut 'pancer.' (Endraswara, 2013) Bahkan Sunan Kalijaga dan sunansunan lainnya menjadi spirit berkesenian bagi pengembang topeng di daerah Cirebon (Marsunan, 2000).

Wayang Topeng Malang adalah pertunjukan yang melibatkan gerak tari, sehingga penyajiannya lebih bersifat dramatari daripada drama. Penyajian tokohtokoh menggunakan gerak tari dan kata-kata (vokal) yang dilakukan dalang. Bentuk topeng Jawa pada umumnya menutup seluruh wajah penari, sehingga penari tidak dapat berkata-kata. Topeng di Malang Jawa Timur juga demikian (Hidajat, 2011).

Setiap topeng yang digunakan untuk pertunjukan menggunakan lakon tertentu. Wayang Topeng di Malang menggunakan repertoar lakon Panji dalam berbagai versi, yaitu memfokuskan pada pengembaraan tokoh Panji yang berasal dari kerajaan di Jawa Timur sekitar abad X-XIII (Sumandiyo, 2005). Karakteristik tokoh dalam lakon Panji itu diwujudkan dalam bentuk topeng-topeng yang diukir. Karakteristik yang digambarkan adalah tokoh Klana Sewandana, Panji Asmarabangun, Gunungsari, Bapang, Ragel Kuning, Sekartaji, dan para prajurit Jawa dan Sabrang (Supriyanto, 1997). Nilai yang dikomunikasikan dari lakon panji itu adalah estetika simbolis yang membedakan antara 'Jawa' yang dianggap sebagai wujud tingkah laku orang Jawa yang alus, dan 'sabrang' yang dianggap sebagai wujud tingkah laku orang dari seberang, orang luar Jawa yang selalu mengancam ketentraman kehidupan orang Jawa (Hidajat, 2011).

Lakon Panji pada Wayang Topeng di Desa Kedungmonggo Malang menggunakan topeng-topeng yang dibuat dengan cara dan teknik tertentu. Dorongan untuk mengetahui fungsi dan teknik pembuatan topeng tradisional ini membawa peneliti tertarik mengkaji kreativitas perajin topeng tradisional di Desa Kedungmonggo Malang Jawa Timur.

\section{METODOLOGI}

Artikel ini diangkat dari penelitian Robby Hidajat (penulis) berjudul Wayang Topeng Malang (2012).Penelitian ini adalah 
kualitatif, yaitu menggunakan data berupa pernyataan lisan dan penafsiran tindakan informan yang digali langsung dari lapangan.

Pengambilan data melalui wawancara dan pengamatan. Model penelitian ini fenomonologi seni, yaitu memahami aktivitas manusia yang harus dipahami sebagai suatu yang bermakna. Setiap aktivitas individu itu harus diinterpertasikan (Wirawan, 2012). Informan kunci Tri Handaya (40 tahun) seniman, Sukani (67 tahun) perajin topeng dari Tumpang, M. Soleh Adi Pramono (61 tahun) seorang dalang Wayang Topeng dari Tumpang. Data diperoleh melalui observasi dan wawancara mendalam, khususnya pada proses pembuatan topeng. Analisis menggunakan interpertafif dan dituangkan secara diskriptif

\section{HASIL DAN PEMBAHASAN Paparan Data}

Topeng adalah benda yang tidak termasuk dalam pengertian busana, sungguhpun topeng dipakai dan melekat pada bagian sosok penari. Topeng menjadi sesuatu yang perlu dijelaskan tersendiri, termasuk proses pembuatannya. Karena topeng memiliki kaitan dengan pemahaman masyarakat pendukungnya, termasuk eksistensi topeng terhadap pola pikir setiap perajinnya. sehingga cara mengukir juga mengalami perkembangan sesuai dengan zamannya.

Kegiatan yang berkaitan dengan aspek magistis dalam proses pembuatan topeng, yaitu dilakukan mulai dari memilih dan memotong kayu. Topeng-topeng yang diharapkan memiliki tuah selalu diambil dari pohon-pohon yang tumbuh di pinggirpinggir sungai atau di tempat yang angker. Meskipun demikian tidak semua kayu dapat dibuat topeng. Hanya kayu-kayu tertentu yang sering kali dipercaya dihuni oleh makhluk-makhluk halus, yaitu seperti kayu Pule (Alstonia scholaris), kayu Dadap (Erythrina subumbrans [hassk.] Merr.), kayu Cangkring (Erythrina Lithosperma Mig.), kayu Kembang (Canangium odoratum), atau kayu Nyampo (Calophyllum inophyllum L.). Karena kayukayu tersebut kini susah untuk dicari, dengan demikian para perajin topeng di Desa Kedungmonggo lebih banyak menggunakan kayu Sengon Laut (Atocasia macrorhiza schott).

Menurut Karimun pemilihan kayu yang tumbuh di tempat yang sunyi, dapat dipastikan kayu itu selalu dihuni oleh makhluk halus. Oleh sebab itu sewaktu pemotongan kayu dibutuhkan cara spiritual. Agar roh penunggu kayu tidak marah dan bersedia tempat tinggalnya dipotong. Perajin topeng tidak dapat memaksa, jika roh yang menghuni kayu tidak mengijinkan. Jika memang dibutuhkan sekali, perajin harus melakukan usaha-usaha spiritual agar makluk halus bersedia pindah. Kayu yang ditebang dan dipotong-potong untuk bahan membaut topeng. Tahap ini disebut mbakali.

Karimun yang sudah membuat topeng sekitar tahun 1935 menceritakan hal-hal magis berkaitan dengan topeng buatannya sebagai berikut: Topeng itu sebenarnya tidak sekedar alat penutup wajah penari, ada “yoni'-nya (kekuatan magis). Membuat topeng tidak boleh sembarangan, ada perilaku spiritual. Namun, para perajin sekarang ini tidak lagi memperhatikan aspek spiritual. Perajin topeng pada zaman dahulu, apabila membuat topeng kayunya terbalik (bagian ujung di bawah), dapat berakibat penari yang memakai kalap (trance). Penari senantiasa terus menari, tidak mau berhenti. Bahkan ada penari yang pingsan (Handoyo, 2013).

Pemahaman Karimun, topeng itu adalah kedok, yaitu tempat yang cekung untuk 
tempat muka. Pengertian kedok adalah berfungsi untuk menutup muka. Kedok dimungkinkan berakar dari kata ledok yaitu sebidang tanah yang dikosongkan untuk bertanam padi (tempat bertanam padi) yang disebut Kedokan (bersumber dari istilah ledok) (Hidajat, 2011).

Menurut Madya Utama (1925-1970), tokoh topeng dari Desa Jatiguwi Sumberpucung, menerangkan bahwa topeng mempunyai pengertian: Wenang ndhelok, dhak wenang di dhelok (Bisa melihat, tetapi tidak bisa dilihat). Pengertian ini berkaitan dengan fungsi topeng sebagai tempat yang cekung untuk memasukkan muka. Pengertian itu menunjukan bahwa topeng itu adalah tempat untuk membenamkan wajah (Chattam, 2012). Pengertian membenamkan wajah, dapat dipahami menyembunyikan. Sehingga topeng itu berfungsi untuk menyembunyikan wajah asli agar tidak dapat dilihat oleh orang lain. Ini artinya adalah usaha untuk menyamarkan diri atau beralih rupa. Dalam bahasa wayang disebut 'palihan'.

Pada umumnya topeng yang memiliki tuah membuat penari tidak capek dan juga tidak terasa sedang menari, tetapi jika tidak dipelihara dengan baik maka roh di dalam topeng akan marah. Topeng Gunungsari yang digunakan setiap pentas pernah tidak dibawa ketika pentas di Pancakusuma, topeng itu di dalam kotak terdengar seperti membentur-bentur dinding kotak (bahasa Jawa: gemlodhak). Ada yang kerasukan ketika memakai. Pengalaman Rasimun, topeng Gunungsari yang dikenakan tidak dapat dilepas ketika selesai digunakan pentas.

Seorang perajin topeng ketika akan membuat topeng harus bersih hatinya, bahkan jika membuat topeng yang khusus memang untuk seorang penari yang bagus. Topeng yang harus disiapkan juga harus bagus. Fungsi topeng yang berkualitas adalah untuk membuat penari benar-benar nyaman. Bahkan topeng yang dibuat dengan cara yang khusus itu juga disiapkan agar roh dapat memberikan kekuatan spiritual, sehingga penonton dapat memperoleh pengalaman estetik secara mendalam.

Kalau topeng ingin ada 'isi'nya (kekuatan magis), pengukir topeng akan membawa ke pundhen desa untuk di-strenkan. Topeng yang dimohonkan tuah (istilah tradisi Bali 'ngerehin') untuk penari yang berkualitas. Karimun pernah punya topeng Klana. Topeng itu di-stren-kan, roh yang menempati topeng itu tempramentalnya garang. Ketika Karimun menggunakan topeng itu menari, semua penonton diam.

Rasimun (1921-1980) selah satu perajin topeng dari Desa Gelagahdowo, Tumpang, menjelaskan untuk membuat topeng memang harus melakukan puasa, apakah puasa mutih atau puasa ngebleng (tidak makan sehari penuh). Tetapi yang penting adalah mengikrarkan niat untuk dapat mendatangkan roh dari tokoh yang dikehendaki. Jika permintaan itu dikabulkan, topeng itu akan memiliki tuah yang besar. Setidaknya jika digunakan menari kelak akan mempunyai kharisma yang dapat menyenangkan penonton. Pengalaman para penari yang memiliki topeng bertuah sama seperti orang yang memiliki keris. Pada setiap hari tertentu, umumnya Jumat Legi selalu disuguh dengan sesaji dan dibakarkan dupa. Apabila tidak dilakukan, seringkali ada tanda-tanda tertentu, misalnya topeng berbunyi gemlodhak di dalam lemari, atau melalui mimpi ada seseorang yang datang minta minum (Adipramono, 2012).

Perajin topeng tradisional di Malang secara teknik mempu menangkap getaran imaji, hanya saja tidak dijumpai istilahistilah khusus pada tindakan magis yang 
dilakukan. Kangsen, perajin topeng dari Jabung, Tumpang. Apabila topeng yang dilakukan pada waktu malam hari di dalam bilik kamarnya. Dia tidak keluar jika topeng itu belum selesai, maka selama proses itu juga dilakukan puasa (Supardjo, 2012).

Para pengukir topeng di Malang umumnya bukan topeng profesional, mereka adalah para petani. Proses pembuatan topeng memiliki kaitan dengan pemahaman istilah agraris, seperti balala (bahan yang disiapkan). Karimun juga pernah menyebutkan sebelum mengukir raut topeng disebut 'wiwit'.

Tradisi pembuatan topeng-topeng sakral di Bali disyaratkan melakukan tindakan spiritual, seperti memilih kayu yang memiliki tuah, berpuasa atau membuat sesaji khusus setelah atau sesudah pembuatan topeng. A. Agung Suryahadi dalam artikelnya berjudul "Topeng Tradisional Bali" mengemukakan bahwa topeng yang akan digunakan sebagai sarana upacara, proses akhir pembuatannya dilakukan acara yang bersifat ritual seperti: upacara Prayascita yaitu pembersihan topeng secara niskala. Kemudian agar topeng memiliki daya "taksu", dilakukan upacara Pasupati. Pada upacara tersebut mereka memohon kepada Tuhan Yang Maha Esa agar kekuatan-Nya berada pada topeng. Agar memiliki daya supranatural maka upacara ngerehin diadakan. Topeng jenis ini sangat sakral, yaitu memiliki kekuatan magis dan disimpan di pura dalam ruang khusus.

Topeng yang sempurna mengalami proses akhir pemeradaan (dicat prada) adalah sudah selesai diukir bentuk raut muka sesuai dengan karakter tokoh tertentu. Karimun menyebut sebagai proses 'meraeni' (mengukir wajah). Setelah itu diukir jamang dan sumping sebagai bagian yang menunjukan ciri khas sebagai topeng alus atau gagah.

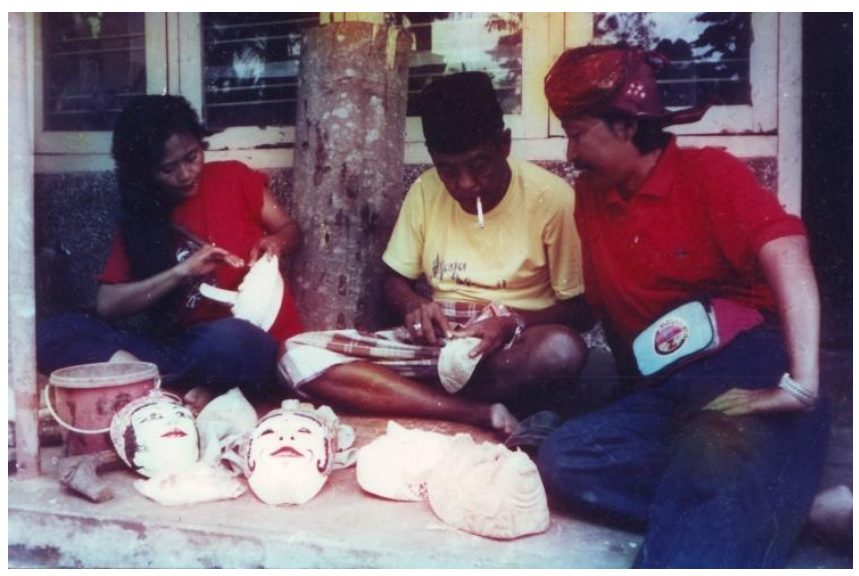

Gambar 1. Keluarga Karimun yang merintis kerajinan topeng di Desa Kedungmonggo- Malang

\section{Analisis}

\section{Fungsi Topeng}

Topeng pada Wayang Topeng Malang adalah topeng yang digunakan untuk menari. Tujuannya adalah untuk mengganti rias wajah, sehingga penampilan tokohtokoh dalam lakon Panji digunakan topeng. Karakter-karakter tokoh yang digambarkan melalui topeng itu disesuaikan dengan perwatakan tokohnya. Misalnya Panji Asmarabangun adalah tokoh protagonis yang berwatak alus. Topeng digambarkan dengan kontur raut wajah topeng yang oval, mata gabahan (seperti bulir gabah), bibir tersenyum (delima meletek) dan berkumis tipis. Tokoh Kelana Sewandana adalah tokoh antagonis (lawan) yang digambarkan melalui topeng yang bulat persegi, mata melotot (telengan), bibir terbuka tampak giginya (prengesan), dan berkumis tebal (kepelan).

\section{Proses Pembuatan Topeng}

Perajin topeng tradisional di Desa Kedungmonggo pada waktu mengukir topeng dikerjakan melalui proses yang 
bertahap, yaitu mbakali atau membuat bakalan, wiwit, dan dilanjutkan dengan meraeni, dan maesi. Tahap akhir adalah mengukir ornamen dan pengecatan. Langkah-langkah pembuatan topeng itu sebelum Taslan Harsono belum disadari. Karena yang lebih dipentingkan mengisi kekuatan magis pada topeng. Setelah Taslan Harsono mendapatkan pelatihan mengukir topeng Bali, Taslan Harsono menyadari tentang proses. Karena tahapan itu dibutuhkan untuk metode mengajar.

a. Proses Pembuatan Topeng Malang

Warisan proses pembuatan topeng saat ini dilanjutkan putranya bernama Tri Handoyo, yaitu sebagai berikut:

\section{i. mBakali}

Tahap pertama. Kayu yang ditebang kemudian dibelah. Tahap awal ini disebut mBakali. Prosesnya, kayu gelondongan dipotong sepanjang kurang lebih 25 - 30 $\mathrm{cm}$. Berikutnya dikeringkan agar kadar airnya berkurang. Pengeringan dilakukan di tempat teduh yang tidak lembab, sehingga panas sinar matahari tidak langsung terkena kayu. Setelah siap untuk dibuat topeng, kayu-kayu yang telah dibelah ditaruh pada 'salang' (parapara) di dapur. Topeng diletakkan di para-para itu sekitar $2-3$ bulan. Secara kronologis, langkah pertama pengerjaan topeng ditunjukkan pada Gambar 2.

Demikian kronologis dari bakalan topeng, tahap ini terdiri dari 4 langkah. Bakalan merupakan langkah awal, yaitu memulai untuk membuat perwujudan. Pada langkah ini belum ada tanda-tanda bahwa kayu itu akan dibentuk menjadi perwujudan topeng. Karena pada tahap ini bisa jadi gagal, kalau gagal 'bakalan' tersebut akan jadi kayu bakar.

ii. Wiwit

Tahap selanjutnnya adalah tahap ke dua, yaitu tahap "wiwit". jika orang bertani tahap ini disebut dengan "ngurit", yaitu menyemai padi. Pada tahap ini sudah ada niat yang ditumbuhkan, yaitu memulai untuk membuat perwujudan topeng. Tetapi belum ada tanda-tanda akan dijadikan topeng jenis apa.

Tahap "wiwit" ini dimulai ketika kayu telah menjadi pola segi tiga. Kemudian tiga perempat bagian dari atas di gergaji untuk menentukan posisi hidung.

Setelah tahap ini kemudian topeng mulai diraut menentukan pola oval dan dilanjutkan mencekungkan bagian dalam untuk tempat muka.

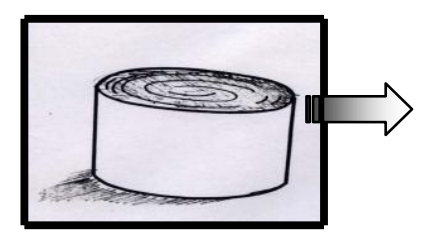

1

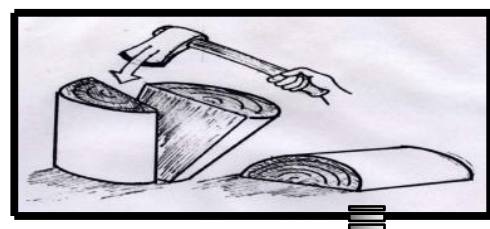

2
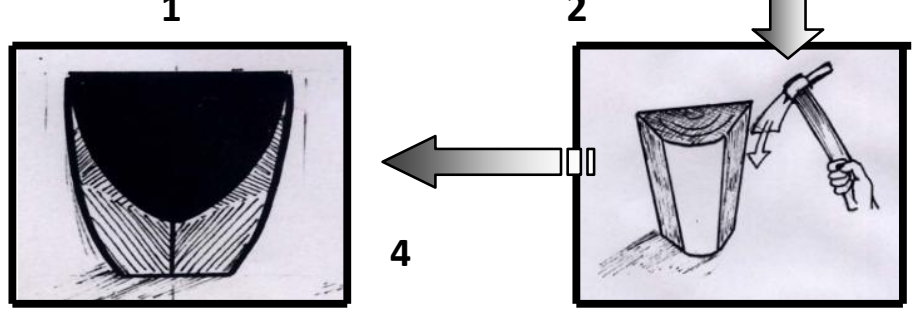

3

Gambar 2. Empat Langkah pada Proses Bakalan pembuatan topeng di Malang, Jawa Timur 


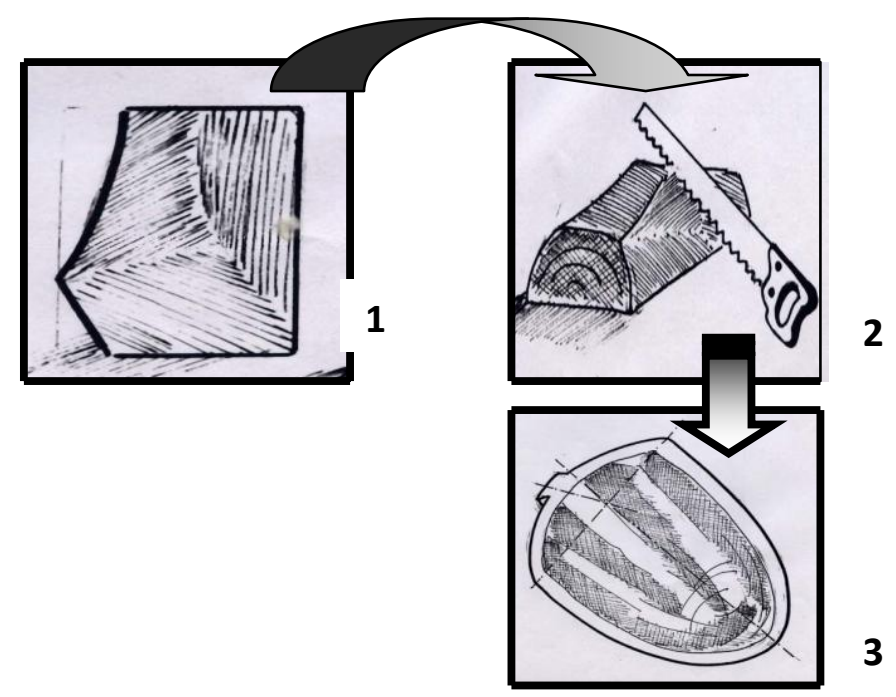

Gambar 3. Tahap "Wiwit", yaitu tahap memulai menentukan jenis topeng

\section{iii. Meraeni}

Tahap berikutnya "meraeni", artinya menentukan wujud muka, yaitu menentukan posisi mata, hidung, dan, mulut. Teknik pengerjaan pada bagian ini semula digunakan pangot (pisau untuk tukang sol sepatu), akan tetapi setelah Taslan Harsono mendapatkan pelatihan di Dinas Perindustrian Denpasar, Bali, teknik meraeni menggunakan tatah ukir. Sekarang perajin-perajin muda di Desa Kedungmonggo sudah terbiasa menggunakan tatah ukir.

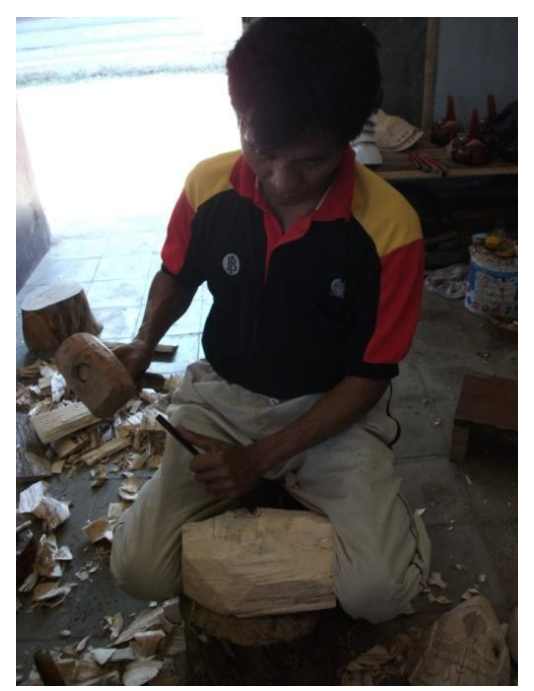

Gambar 4. Raimun, salah satu perajin topeng yang menggunakan tatah ukir untuk mengukir bagian wajah topeng
Raimun, salah satu perajin muda di Desa Kedungmonggo merasa lebih mudah menggunakan tatah ukir dari pada menggunakan pangot (Raimun, wawancara 12 Juli 2013).

Topeng tampak menjadi 4 bagian pokok, yaitu bagian atas disebut 'jamangan', 'mata-hidung', 'mulut', dan bagian bawah adalah 'dagu'. Bagian-bagian ini menentukan jenis dan karakter topeng tertentu, setidaknya alus atau gagah.

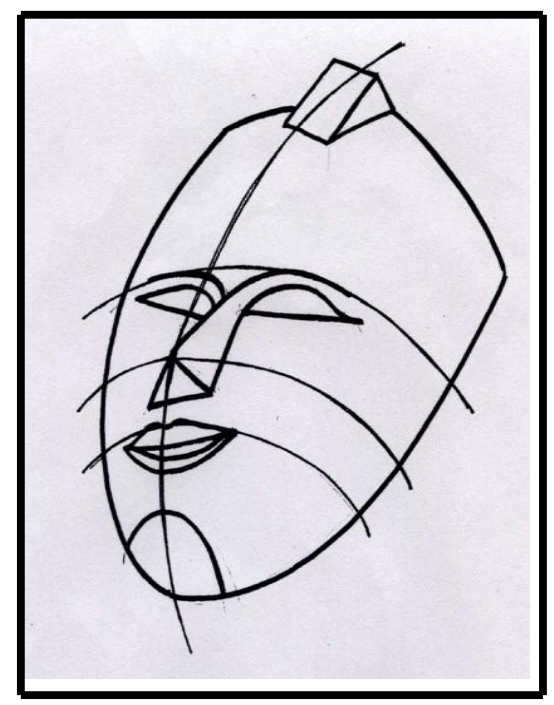

Gambar 5. Komposisi pada saat mengukir raut muka 
Tahap berikutnnya adalah menentukan ukiran pada 'jamang' dan 'sumping'. Bagian ini secara tradisional menggunakan ukuran jengkalan dan jari. Pada prinsipnya pembagian didasarkan pada proposi hasil banding antara bagian. Seperti terlihat pada jangka, mata kaki jangka berada pada 'urna' (ukiran pada dahi) sebagai pusat topeng. Bagian ini membagi dua bagian kiri dan kanan, kemudian membagi tiga bagian ke atas, yaitu bagas 'rambut' dan posisi 'cula' bagian atas yang menonjol.

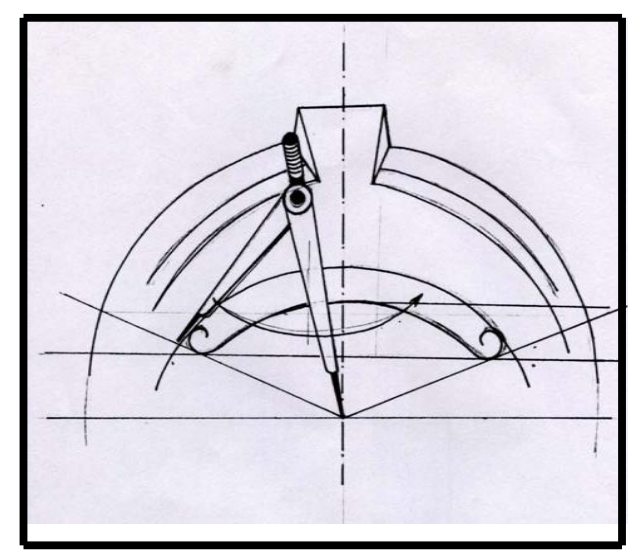

Gambar 6. Gambar rancangan pembagian ukiran untuk Jamang
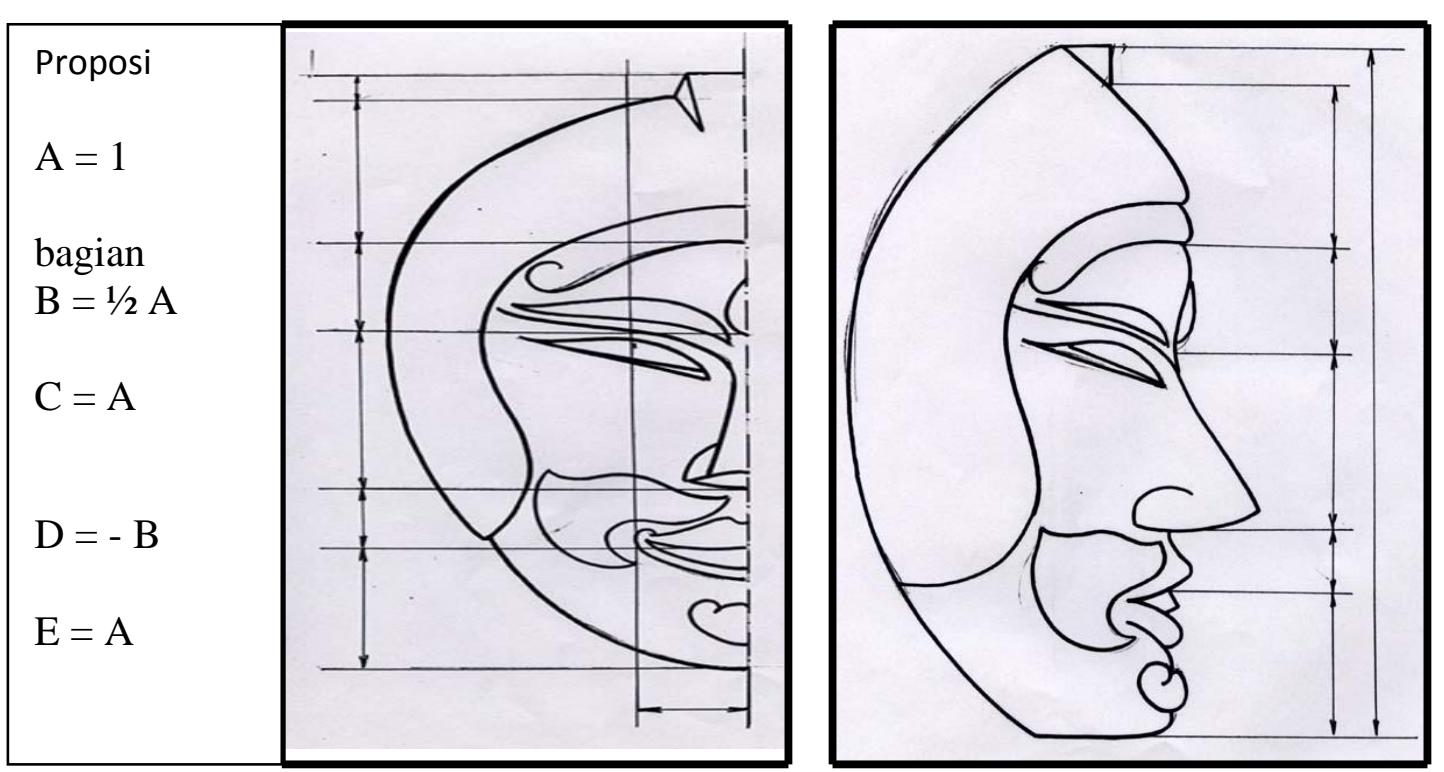

Gambar 7. Gambar bagian-bagian 'praen' atau wajah topeng. Pada bagian ini telah menampakan karakter topeng. Gambar di atas menunjukkan karakter tokoh gagah

Perajin tradisional umumnya menggunakan ukuran jengkal dan ukuran 'nyari' (jari), yaitu ukuran selebar jari tangan. Ukuran topeng secara keseluruhan dari atas ke bawah panjangnnya 1 jengkal 3 jari, lebar topeng 1 jengkal untuk topeng alus, untuk topeng gagah ditambah dua jari. Pada perkembangan cara mengukur, jengkal mulai ditinggalkan, alat yang digunakan adalah jangka kaki.

Tahap mengukir di lakukan setelah tahap 'meraeni'. Pada tahap ini sudah menampakan jenis dan karakter topeng. Tahap ini meliputi langkah-langkah mengukir dan mengecat. Seperti halnya kebiasaan masyarakat di desa-desa. Jika mereka mendirikan rumah selalu dilakukan tahap-tahap konstruksi. Tanda konstruksi yang dilakukan adalah mendirikan kuda-kuda yang terlebih dahulu harus diselamati. Setelah selesai dilakukan tahap membenahi bagian depan rumah, termasuk mengecat kusen, pintu, dan jendela. Tahap akhir dari 'meraeni' tampak pada gambar 7 . 
Jangka kaki digunakan Taslan Harsono berasal dari pelatihan pembuatan topeng di Denpasar Bali tahun 1976. Penerapan pada komposisi pada raut wajah topeng seperti pada gambar di atas, yaitu $\mathrm{A}=1$ bagian, yaitu digunakan ukuran pada lebar jamang dan gagu ke bibir. B menggunakan $1 / 2 \mathrm{~A}$, dan ukuran lekuk pangkal hidung ke bibir $=$ A.

Rumus ini digunakan bagi mereka yang belajar. Sekarang ukuran yang pernah diterapkan oleh Taslan Harsono waktu diminta untuk mengadakan pelatihan pembuatan topeng. Pengukir-pengukir muda setelah generasi Taslan Harsono sudah tidak lagi menggunakan sistem pembagian tersebut.

iv. Maesi

Maesi atau paes, yaitu menghias muka (make up). Tahap ini pada dasarnya adalah memberikan ornamen hiasan topeng, yaitu terdiri dari mengukir ikat kepala (irah-irahan) dan mahkota (jamang). Ornamen topeng Malang umumnya didominasi bentuk bungabungaan, buah-buahan, lung-lungan (sulur pendek), dan binatang sejenis naga, garuda, dan pola geometris (Sukani. wawancara tanggal 10 Mei 2013).

Umumnya ornamen topeng Malang dibedakan menjadi dua kelompok berdasarkan karakteristik tokoh: 1) tokoh alus (satria dan raja) menggunakan ornamen berbentuk bunga dan buahbuahan, 2) tokoh gagah atau kasar menggunakan bentuk ornamen binatang sejenis naga atau garuda dan pola geometris.

Ornamen jenis bunga dan buah terdapat pada hiasan mahkota topeng yang diukir secara simetris (seimbang kanan dan kiri), bunga dan buah berpadu mengacu pada sifat kodrati tumbuhan, yaitu sebuah pengharapan tentang terwujudnya sebuah generasi baru (biji yang tidak diukir atau dilukiskan). Hiasan mahkota topeng salah satunya ditunjukkan pada Gambar 8.

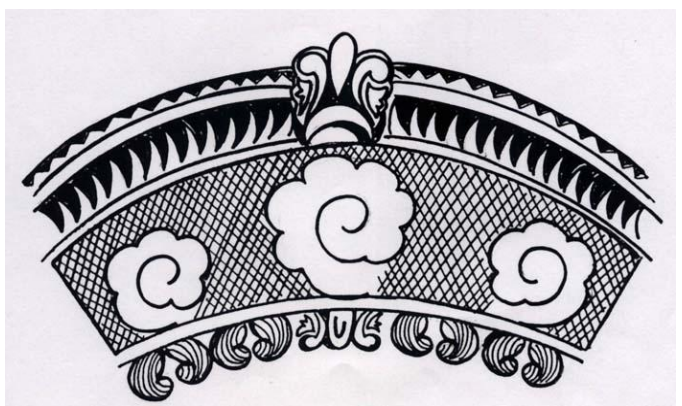

Gambar 8. Ornamen hiasan mahkota topeng berukir pola bunga sederhana

Ornamen untuk satria yang berwatak gagah, seperti Kartolo atau Brajanata seringkali menggunakan ukiran berbentuk bunga yang diukir simetris, tujuannya untuk menampakkan kesederhanaan dan kekokohan, di samping menunjukkan sifat yang maskulin. seperti pada Gambar 9.

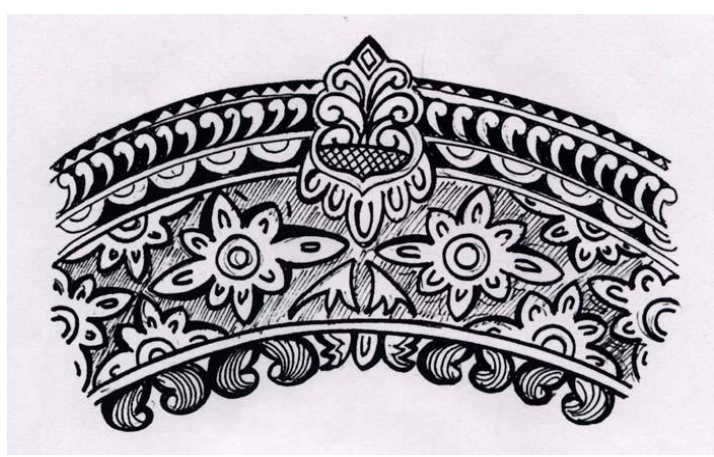

Gambar 9. Ornamen hiasan mahkota topeng berukir pola bunga

Ornamen topeng selain pada mahkota juga diukir pada bagian pelipis kiri dan kanan yang disebut 'sumping'. Pola ukiran pada sumping ini dibedakan juga menurut karakter atau tokoh tertentu. Tokoh-tokoh yang berkarekter gagah umumnya mempunyai ukiran sumping 
berpola seperti mulut naga menganga yang disebut asu jegog. Ukiran bentuk asu jegog ini diukir menghadap ke depan. Bentuk ukiran asu jegog adalah sebagai hasil adaptasi dari bentuk ukiran kepala garuda.

Menurut Soedarsono, ukiran garuda yang umumnya disebut garuda mungkur, 'garuda menghadap ke belakang' ornamen yang usianya sangat tua. Bentuk itu telah dikenali di berbagai relief candi-candi di Jawa Timur sekitar abad X - XVI. Ornamen naga dan garuda yang semula sebagai atribut raja dan satria, pada perkembangannya mengalami perubahan sebagai hiasan kepala yang memiliki kekuatan pelindung, tolak balak (Soedarsono, 1984/85).

Bisa jadi penggambaran bentuk binatang yang mulutnya menganga itu adalah sejenis rajah (torehan magis) untuk tolak balak (pengusir kekuatan jahat atau nasib sial). Bentuk hiasan mulut binatang menganga pada sumping dapat dilihat pada Gambar 10.

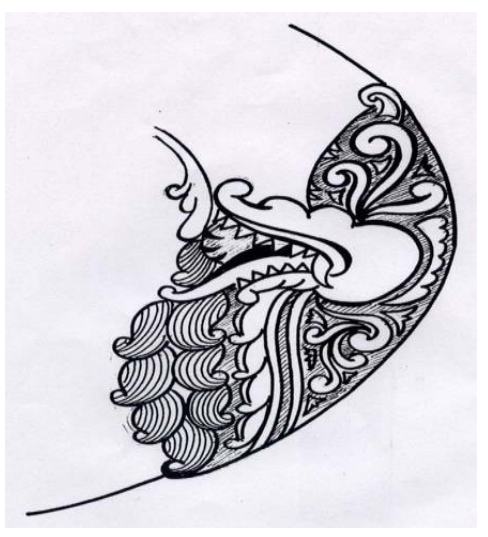

Gambar 10. Ukiran ornamen 'mulut naga' pada sumping topeng. Ornamen ini untuk topeng jenis topeng gagah

Menyimak pola ornamen topeng dan hiasan kepala (jamang) dan sumping. menunjukkan adanya sisa-sisa paham totemistik. Gambar-gambar itu tidak hanya dimaksudkan sebagai simbol tokoh yang menunjukkan karakteristiknya. Tetapi dimungkinkan para pemakainya merupakan golongan atau klan tertentu. Hal ini dapat ditunjukkan pada bentuk hiasan topeng 'Klana'. Ornamen topeng Klana Sewandana berbentuk bunga melati (Jasminum sambac) yang merekah. Ornamen melati menunjukkan sifat abadi, kekal, atau lambang kekuasaan.

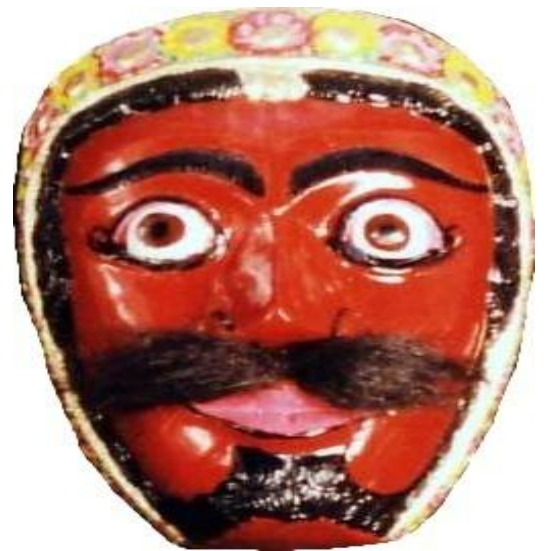

Gambar 11. Foto raut wajah topeng Klana Sewandana. Ornamen bunga melati melingkar seluruh bagian tepi raut wajah topeng

\section{b. Peralatan}

Peralatan ukir yang utama dapat dikemukakan sebagai berikut:

i. Pada proses wiwit digunakan peralatan potong dan belah. Peralatan potong umumnya menggunakan gergaji kayu. Peralatan belah menggunakan kapak.

ii. Pada proses meraeni digunakan peralatan jenis pisau dan pangot. Pangot besar digunakan untuk mengurangi bagianbagian kayu yang lebar misalnya mengurangi dan membentuk bagian dahi (bagian jamang) dan bagian pili. Pada tahap ini juga dilakukan proses mengledoki (membuat cekungan untuk tempat wajah penari). Peralatan yang 
digunakan tatah kayu dan dilanjutkan dengan pangot.

iii. Pada proses maesi (menghias muka) digunakan jenis pisau dan pangot kecil. Perkembangan keterampilan para pengukir topeng di Desa Kedungmonggo pada saat ini banyak yang menggunakan alat ukir kayu (jenis alat ukir Bali).

Peralatan ukir topeng yang digunakan oleh para perajin topeng di Desa Kedungmonggo seperti pada Gambar 12.

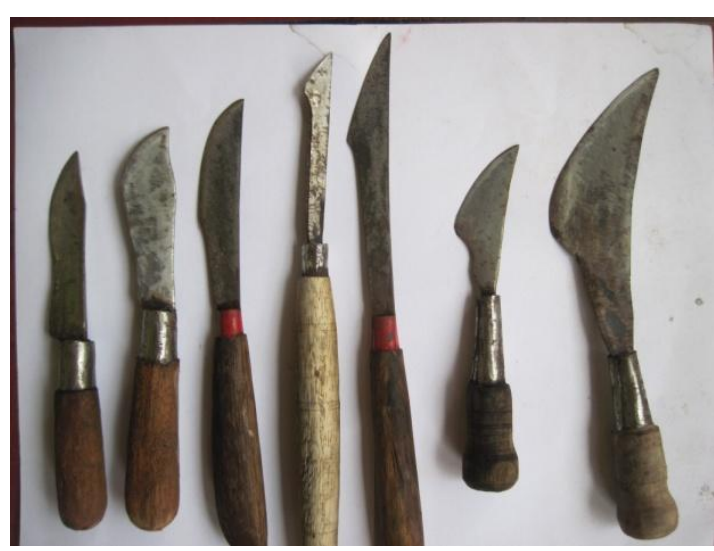

Gambar 12. Jenis pisau dan pangot untuk mengukir topeng di Desa Kedungmonggo

\section{KESIMPULAN DAN SARAN}

Kerajian topeng yang berkembang di Desa Kedungmonggo Malang Jawa Timur hasil karya perajin tradisional. Pada umumnya, perajin topeng secara turun temurun cara tradisional. Bahkan setiap perajin disyaratkan menguasai ajaran spiritual. Sehingga mereka menjadi peka lingkungan. Pohon yang akan ditebang harus dipilih melalui tirakat dan sesaji. Mengingat topeng-topeng yang mereka kerjakan pada umumnya adalah untuk pertunjukan. Para penari yang memakai topeng dapat dengan mudah menghayati karakteristik tokoh. Misalnya: Topeng Panji Asmarabangun berwatak alus (halus) mampu melahirkan stimulus gerakan yang halus, demikian juga penari yang menggunakan topeng Klana Sewandana. Tokoh ini mempunyai karakteristik yang gagah (kasar), penari dapat mengungkapkan gerak yang tegas dan kuat.

Para penari terlebih dahulu dibawa ke pundhen desa. Oleh karena itu, perajin topeng tradisional juga tidak sekedar mengukir topeng. Mereka selalu melakukan upaya spiritual. Tujuannya agar penari yang mengenakan topeng dapat merasa kehadiran roh-roh leluhur dan penontonnya merasakan sugesti atas kehadiran roh-roh yang dihadirkan.

Proses pembuatan topeng melalui beberapa, yaitu 'bakalan' atau 'mbakali' adalah tahap menunju 'wiwit'. Mbakali ke wiwit adalah proses kehidupan, seperti halnya para petani menyiapkan pembenihan. Kebiasaan itu tampak direfleksikan dari tradisi para petani yang sedang menyiapkan tanam padi. Tahap berikutnya adalah 'meraeni'. Ini terkait dengan orang membangun rumah. Jika secara konstruksi rumah tradisional sudah dibentuk, kemudian membenahi bagian depan (eksterior). Diperhatikan cara pengecatan, ukiran atau karakter topeng yang mantap.

Karimun mewariskan keterampilan kerajinan topeng pada para perajin muda di Desa Kedungmangga memiliki harapan bahwa, lingkungan (pohon) tidak diperlukukan sebagai benda tak bernyawa, asal ditebang. Bahkan penari yang mengenakan topeng kayu itu tidak asal di pakai. Fungsi dan proses pembuatan topeng yang dilakukan oleh Karimun adalah sebuah ritus penghormatan roh yang ada pada setiap benda, termasuk pohon. Bahkan topeng yang telah dibuat harus mendapatkan perlakuan yang layak, karena di dalamnya tersimpan roh-roh leluhur. 


\section{DAFTAR PUSTAKA}

Adipramono, M.S. 2012. Wawancara tanggal 16 Juli 2012 di Malang.

AR., Chattam. 2012. Wawancara tanggal 10 Juli 2012 di Malang.

Endraswara, S. 2013. Memayu Hayuning Bawana: Laku Menuju Keselamatan dan Kebahagiaan Hidup Orang Jawa. Yogyakarta: Narasi.

Gustami, S.P. 2006. Kearifan Ekosistem dalam Berkesenian. Dalam Agus Burhan (Ed.). Jaringan Makna Tradisi hingga Kontemporer. Yogyakarta: BP ISI Yogyakarta.

Handoyo, T. 2013. Wawancara tanggal 2 Juni 2013 di Malang.

Hidajat, Robby. 2008. Wayang Topeng Malang. Malang: Gantar Gumelar.

Hidajat, Robby. 2011. Refleksi Konsep Macapat pada Karakteristik Penokohan Wayang Topeng Malang. Jurnal Seni dan Budaya Gelar. Vol. 9, No. 2.

Hidajat, Robby. 2011. Wayang Topeng Malang: Kajian Struktural Simbolis Seni Pertunjukan Tradisional di Malang Jawa Timur. Malang: Gantar Gumelar.

Ks. 2003. Mbah Karimun: Perajin dan Penari Topeng Malang. Jurnal Bende No 1.
Marsunah, Juju. 2000. Sawitri: Penari Topeng Losari. Yogyakarta: Tarawang.

Raimun. 2013. Wawancara tanggal 12 Juli 2013 di Malang.

Soedarsono, 1997. Wayang Wong: Dramatari Ritual Kenegaran di Keraton Yogyakarta. Yogyakarta: Gadjah Mada University Press.

Sukani. 2013. Wawancara tanggal $10 \mathrm{Mei}$ 2013 di Malang.

Sumandiyo, Y. Hadi. 2006. "Wayang Topeng dan Cerita Roman Panji dalam Perjalanan Budaya". Dalam Agus Burhan (Ed.). Jaringan Makna Tradisi hingga Kontemporer. Yogyakarta: BP ISI Yogyakarta

Supardjo. 2012. Wawancara tanggal 10 Agustus 2012 di Malang.

Supriyanto, H. \& M.S. Adi Pramono. 1997. Dramatari Wayang Topeng Malang. Malang: Padepokan Seni Mangun Dharmo.

Suryahadi, A. A. 2008. Topeng Tradisional Bali. Makalah dalam Seminar Topeng Tradisional. Malang, 25 Mei 2008.

Wirawan, I,B. 2012. Teori-Teori dalam Tiga Paradigma. Jakarta: Kencana Prenada Media Group. 